\title{
O SISTEMA PENITENCIÁRIO EM TEMPOS DE COVID-19 EM PORTUGAL
}

\section{THE PENITENTIARY SYSTEM IN COVID-19 TIMES IN PORTUGAL}

\author{
Manuel Monteiro Guedes Valente
}

\section{Sumário:}

1. Enquadramento geral do tema

2. O sistema penitenciário português face à pandemia gerada pelo COVID-19

3. Os patamares operativo e organizativo

4. O patamar político-legislativo

4.1. Do perdão da pena: total ou parcial

\subsection{Do indulto excecional}

\subsection{Das licenças de saída administrativa extraordinária}

4.4. Da adaptação à liberdade condicional

5. Do patamar judicial de intervenção do Estado

Conclusão

Palavras-Chave: Sistema penitenciário, humanidade, espaço, perdão, indulto, saída administrativa, liberdade, reexame excecional

\section{Summary:}

1. General framework of the theme

2. The Portuguese prison system in the face of the pandemic generated by COVID-19

3. Operative and organizational levels

4. The political-legislative level

4.1. Pardon of the prison sentence

\footnotetext{
${ }^{1}$ Este texto corresponde, em parte, à conferência e debate levado a cabo pelo IURJ - Instituto Universitário do Rio de Janeiro, no dia 28 de abril de 2020, via on-line, em que participaram os Juízes Desembargadores Nelson Messias de Morais e José de Ribamar Froz Sobrinho.

2 Doutor em Direito pela Universidade Católica Portuguesa Presidente do Instituto de Cooperação jurídica Internacional. Professor Associado da Universidade Autónoma de Lisboa. Professor do Programa de Mestrado e Doutoramento em Ciências Criminais da PUC-RS. Professor Convidado da ESP-ANP/PF. Advogado e Jurisconsulto.manuelvalente@icji.pt https://www.cienciavitae.pt/portal/0519-A6D2-36EC ORCID: HTTPS://orcid.org/0000-0002-8787
} 


\subsection{Exceptional pardon}

4.3. Extraordinary administrative leave licenses

4.4. From adaptation to conditional freedom

5. The judicial level of State intervention

Conclusion

Keywords: penitentiary system, humanity, space, pardon, administrative exit, freedom, exceptional judicial review.

\section{Enquadramento geral do tema}

O estudo ou análise, minimamente honesta científica, do sistema penitenciário ou a resposta político-jurídica aos problemas do sistema penitenciário em tempos de crise como o atual COVID-19 - impõe que se faça dentro do designado sistema penal integral ${ }^{2}$ - Direito penal material, o Direito penal processual e o Direito penal penitenciário -, subsumido ao sistema jurídico-constitucional legítimo, válido, vigente e efetivo deste tempo e de um determinado espaço.

Esta assunção assenta no pensamento de que as penas que não derivem da necessidade da sua aplicação e manutenção são tirânicas ${ }^{3}$, assim como de que a proporcionalidade das penas deve contrariar a malícia e "as paixões violentas, filhas do fanatismo e do entusiasmo" para que se promova humanidade e uma justiça humana contrária à "imperscrutável malícia do coração" (Beccaria, 1998, 74 e 76).

O tempo que vivemos (ou temos vivido) é um tempo diferente e, caso não se tomem os devidos cuidados, propício a posições tirânicas e autoritárias e de controlo total dos cidadãos em prol de uma cognitiva segurança e saúde públicas. Razão pela qual este tempo deve assentar em um regime diferenciado tendo em conta o estado de emergência decretado e, posteriormente, do estado de calamidade que irá ser (foi) declarado.

Este olhar jus criminal e juscriminológico só pode ocorrer se for um olhar sob o sistema político-constitucional que, por um lado, admite em democracia estados de exceção ou estados de maior restrição de direitos, liberdades e garantias fundamentais, e, por outro, obriga os órgãos de

\footnotetext{
${ }^{1}$ Quanto a este temos e para mais desenvolvimentos se pode ler a nossa tese de doutoramento, defendida em $2012 \mathrm{e}$ publicada em 2013 (pp. 31 e ss.), assim como Mário Ferreira MONTE, na mesma linha, mas com uma sistemática diferente, fala-nos de um "sistema integral de direito penal", que não se confunde com a ciência conjunta do direito penal ou a ciência do direito penal total (Gesamtstrafrechtswissenschaft) de Franz von Liszt, que "engloba várias ciências que, embora autónomas, contribuem para o mesmo fim, completando-se funcionalmente". O sistema integral do direito penal "estabelece uma relação entre o direito penal material, o direito processual penal e o direito de determinação da pena" (Monte, 2008, p. 745).

2 Pensamento de MONTESQUIEU adotado por Cesare BECCARIA para demonstrar que "todo o acto de autoridade de um homem sobre outro homem que não derive da absoluta necessidade é tirânico" (BECCARIA, 1998, p. 64).
} 
soberania, legislativo e judicial - judiciário -, a propugnar uma constante fiscalização desses estados que a democracia aceita e tolera de modo a evitar que o núcleo central dos direitos, liberdades e garantias básicas dos cidadãos - livres ou presos - sejam lesados e agredidos pelos poderes públicos ou privados com concessão de atuação pública.

A democracia, melhor, o Estado constitucional democrático ou, na designação de Paulo OTERO (2007, pp. 525 e ss.; 2010, pp. 31-49), o Estado de direitos humanos ${ }^{4}$ - Portugal e o Brasil não pactua com uma ideia de que a tutela dos direitos, liberdades e garantias fundamentais pessoais se processe de forma gradativa conforme o estatuto social, o estatuto profissional, o estado ou situação de vida de cada concidadão - livre ou preso - e muito menos admite que a niilificação do preso seja massificada com o intuito de lhe retirar a essência de pessoa humana, coisificando-o.

Em democracia constitucional todos os seres humanos devem ser tratados com dignidade em igualdade e com igualdade em dignidade. Só assim podemos falar do princípio da humanidade como um dos quatro pilares da social democracia (cristã): justiça, solidariedade, liberdade e humanidade.

Os cidadãos presos estão à guarda - tutela jurídica, judiciária, de segurança e política - do Estado, sobre o qual recai o dever de vigilância [ius vigilandi] em toda a sua dimensão, a mais que, de acordo com o artigo $30 .^{\circ}$, n. $^{\circ} 5$ da CRP, o preso apenas perde o direito de ius ambulandi e mantém todos os demais direitos de vida e vivência: vida, integridade pessoal, saúde, educação etc..

A prisão, no Estado constitucional democrático, não coisifica [não pode coisificar] a pessoa presa nem lhe retira o estatuto de sujeito de direito e sujeito de jurisdição. Apenas lhe restringe o ius ambulandi.

Cabe, assim, ao Estado o dever de garantir que a execução de pena ocorra no respeito pelos demais direitos e garantias fundamentais pessoais, sociais, culturais e políticos compatíveis com a sua condição de preso.

\section{O sistema penitenciário português face à pandemia gerada pelo COVID-19}

O sistema penitenciário tem a sua plenitude de consumação na quinta fase do processocrime comum $-v . g$., execução da pena, desde que ao longo do iter processualis se realizem as fases de inquérito, instrução, julgamento e recurso -, ou seja, concretiza a ação penal e efetiva-a quando a pessoa é condenada a pena de prisão efetiva.

\footnotetext{
${ }^{4}$ Nós designamos o Estado constitucional democrático, enquanto axioma força normogenético-constitucional que limite o poder do Estado, de Estado constitucional de direitos humanos (Valente 2017, p. 297).
} 
Mas, mesmo sabendo-se que não se trata de uma antecipação de cumprimento de pena, nem nunca assim se deve entender, este sistema penal penitenciário encerra em si mesmo uma outra dimensão privativa da liberdade: a medida de coação privativa da liberdade prisão preventiva que pode ocorrer ao longo das fases anteriores do processo $^{5}$, respeitados os limites temporais previstos no artigo $215 .^{\circ}$ do CPP português.

O legislador, quando decide sobre a efetividade do sistema, tem de ter em conta as duas dimensões: a da prisão preventiva e a da execução da pena de prisão. Este múnus agrava-se sempre que estejamos perante uma pandemia cujo efeito de contágio é avassalador e os espaços de distanciamento e cuidado são inexistentes, como é o caso do espaço do sistema prisional ${ }^{6}$ : prisões e carros celulares, cuja estruturação de tutela se projeta para os espaços com detentos como os departamentos policiais e os tribunais.

O COVID-19 tem como caraterística a fácil propagação e avassalador contágio sempre que não existam mínimos de higiene - pessoal e dos locais onde nos encontramos -, não existam condutas humanas de precaução - distanciamento social, uso de máscaras, reduzir ou evitar quaisquer contactos entre pessoas, mesmo familiares -, não exista uma política de saúde pública abrangente e selecionada para determinada franja de pessoas, tais como pessoas com um certa idade, pessoas com doenças que dificultam a prevenção e o tratamento da doença, pessoas que se encontram em espaços de impossível distanciamento social - v. g., as pessoas que se encontram presas (efetivas ou preventivas) e todas as pessoas que trabalham dia-a-dia no espaço do sistema prisional.

A igualdade, enquanto gémea da legalidade, neste cenário, impõe a materialização da sua tetralogia axiológica - tratar igual o que é igual $[=$ é $=]$; tratar diferente o que é diferente $[\neq$ é $\neq]$; tratar igual o que é diferente, mas deve ser igual $[=$ é $\neq,=]$; tratar diferente o que é igual, mas deve ser diferente $[\neq \mathrm{e}=, \neq]^{7}-$, sob pena de enlutarmos muitas famílias por inexistência de uma política pública adequada a prevenir doenças e contágios conducentes à morte de milhares de pessoas.

A política pública [de saúde] tem de assentar em uma política criminal que olhe toda a pessoa presa com a mesma dignidade - dignidade em igualdade e igualdade em dignidade -, e que olhe para todas as pessoas que integram o sistema - guardas prisionais, médicos, enfermeiros dos sistema penitenciário, pessoal de apoio de alimentação e salubridade - como detentoras das mesmas condições de ação e de cuidados preventivos e reativos para evitar a propagação do contágio. Neste tema em concreto, a intervenção do Estado pode e deve passar por vários

\footnotetext{
${ }^{5}$ Cfr. artigos $27 .^{\circ}$, n. $^{\circ} 3$, alínea b), $28 .^{\circ}$ da CRP e artigos $191 .^{\circ}, 192 .^{\circ}, 193 .^{\circ}, 202$ e $204 .^{\circ}$ do CPP português.

${ }^{6}$ Designamos por nós construída tendo em conta a dinâmica espacial em que o sistema prisional/penitenciário se desenrola (VALENTE 2008: 15-75).

${ }^{7}$ Há vários anos que defendemos esta tetralogia do princípio da igualdade, enquanto afirmação de uma legalidade constitucionalmente legitimada (Valente, 2019, pp. 292-297).
} 
patamares que podem implementar-se de forma autónoma ou cumulativa: $v$. g., os patamares operativo e organizativo dos serviços prisionais [poder executivo], legislativo e judicial.

\section{Os patamares operativo e organizativo}

Os patamares operativo e organizativo são da competência da administração do sistema do espaço prisional [Direção-geral dos serviços prisionais], que responde perante o poder executivo, Ministério da Justiça, e que, em Portugal, decidiu (1) interditar as visitas aos reclusos, tendo em conta que o COVID-19 podia entrar nos estabelecimentos prisionais através de pessoas externas e dever-se-ia diminuir ao máximo o maior número de possibilidades de propagação e contágio, (2) criar de um espaço prisional destinado a reclusos e funcionários infetados no hospital prisão e num estabelecimento prisional da zona de Lisboa, (3) reforçar a higiene e a limpeza completa dos estabelecimentos prisionais, boas práticas de etiqueta respiratória [tossir, espirrar e assoar] e da higiene das mãos [pontos de água e sabão em diversas zonas], e (4) equipar [sendo muitas vezes resultado de oferta de instituições de solidariedade social (Misericórdia do Porto)] os funcionários do sistema prisional com máscaras ${ }^{8}$, assim como (5) se proibiu a transferência de reclusos entre os estabelecimentos prisionais, evitando-se possibilidades de contágios.

A esta prática associaram-se os contactos interinstitucionais com a Direção Geral de Saúde de modo a tomar as medidas adequadas a conter ao máximo focos de contágio/contaminação: isolamento e confinamento dos casos detetados como infetados [1 reclusa, 2 guardas prisionais, 1 médico e 1 enfermeira-no dia 1 de abril de 2020].

Esta ação de prevenção do contágio da COVID-19 tem como base a seguinte evolução diminutiva da população prisional de dezembro de 2015, cuja relação de número de presos se cifrava em 14074 para uma lotação de 12 591, com taxa de ocupação de 111,8\% [sobrelotado em $11,8 \%$ ]; conquanto em dezembro de 2019, a relação do número de presos era de 12634 para uma lotação de 12 934, com taxa de ocupação de 97,6\% [espaço livre 2,4\%].

\section{O patamar político-legislativo}

O patamar político-legislativo conduziu o poder político - Assembleia da República - a aprovar a Lei n. ${ }^{\circ}$ 9/2020, de 10 de abril, no âmbito do estado de emergência de saúde pública, devido à pandemia gerada pela doença COVID-19, que estipula o regime de aplicação a reclusos

\footnotetext{
${ }^{8}$ Sobre estas medidas veja-se https://justica.gov.pt/COVID-19-Medidas-adotadas-na-Justica.
} 
- presos - de medidas próprias do designado direito de graça ${ }^{9}$ - perdão e indulto presidencial-, no sentido de o legislador, independentemente das críticas inexoráveis dos demais membros da sociedade, se mostrar humano e indulgente (Beccaria, 1998, p. 162). O legislador aprovou o:

- perdão parcial de penas de prisão, alínea $a$ ) do.$^{\circ} 1$ do artigo $1 .^{\circ}$ e artigo $2 .^{\circ}$;

- regime especial de indulto das penas, alínea $b$ ) do n. ${ }^{\circ} 1$ do artigo $1 .^{\circ}$ e artigo $3 .^{\circ}$;

- regime extraordinário de licença de saída administrativa de reclusos condenados, alínea c) do . $^{\mathrm{o}} 1$ do artigo $1 .^{\circ}$ e artigo $4 .^{\circ}$;

- antecipação extraordinária da colocação em liberdade condicional, alínea $d$ ) do n. ${ }^{\circ} 1$ do $\operatorname{artigo~} 1 .^{\circ}$ e artigo $5 .^{\circ} ; \mathrm{e}$

- regime especial de revisão dos pressupostos da prisão preventiva, assim como o reforço dos princípios da excecionalidade da prisão preventiva, artigo $7^{\circ}$; assim como um

- regime de quarentena dos que regressam ao estabelecimento e dos que entram no estabelecimento prisional [cumprimento de pena ou prisão preventiva], artigo $6{ }^{\circ}$.

O direito de graça é a contraface do poder de punir do Estado, assume-se como válvula de segurança do sistema penal [político-criminal], manifestação do ato de tolerância que legitima o poder de punir e as razões supervenientes, excecionais, comunitárias e individuais (Figueiredo Dias, 1993, pp. 685-698; Liszt 2003, pp. 424-429).

Mas o direito de graça, mesmo tendo surgido como forma de se afirmar numa proporção necessária face ao absurdo das leis e da crueldade das condenações (Beccaria, 1998, p. 161), e para que não se concretize a crítica de um possível relaxamento ou desarmamento da repressão criminal (Pradel, 1999, p. 347), tem limites político-criminais e sociais que o legislador deve ter em conta na promoção da função de equilíbrio do Direito penal.

Importa desde já alertar que o perdão e o indulto excecional assentam em uma seletividade quanto ao tipo fundante da condenação - antijuridicidade e censurabilidade ético-jurídica do factum criminis subjacente à pena aplicada em concreto -, ou seja, há penas referentes a determinados crimes que não são abrangidas por este regime.

O legislador, nos termos das alíneas a) a $n$ ) do.$^{\circ} 6$ do artigo $2 .^{\circ}$ e do $n .{ }^{\circ} 5$ do artigo $3 .^{\circ}$ da Lei

\footnotetext{
${ }^{9}$ Quanto à amnistia enquanto integrante do direito de graça e instituto jurídico ou meio de reposição de paz social DELMAS-MARTY (1986, p. 95), REALE JUNIOR (2013, p. 509), FIGUEIREDO DIAS (1993, p. 1101) e VON LISZT (2003, pp. 424 e ss.). Já alertando para o problema deste instituto jurídico se converter num sistema nocivo por poder fomentar o desarmamento da repressão criminal, PRADEL (1999, p. 347).Veja-se que esta ideia está jacente no pensamento de Enrico Ferri quando crítica a frequência com que Itália concedia amnistia, indultos e perdões de pena, elogiando a posição e as propostas da Escola Positiva em proceder a uma separação do tipo de criminalidade e aos reclusos, que não podem ser habituais, impondo uma nova ordem jurídica contra os abusos indultos e amnistias (2003, p. 165). Sem prejuízo destas posições doutrinárias, é mais que evidente que o direito de graça, perdão, indulto e a própria amnistia são causa supervenientes que negam a procedimentabilidade do exercício da ação penal (Ferrajoli, 2005, p. 574).
} 
n. ${ }^{\circ}$ 9/2020, de 10 de abril, estipulou que não podiam beneficiar do perdão e do indulto excecional todas as pessoas presas que tenham sido condenadas a penas de prisão pela prática dos crimes de:

a) homicídio p. e p., pelos artigos $131 .^{\circ}, 132 .^{\circ}$ e $133 .^{\circ}$ do Código Penal;

b) violência doméstica e de maus tratos, p. e p. pelos artigos $152 . .^{\circ} 152 .{ }^{\circ}$-Ado CP;

c) contra a liberdade pessoal, p. e p. pelos artigos do capítulo IV do título I do livro II do $\mathrm{CP}$;

d) contra a liberdade sexual e autodeterminação sexual, p. e p. pelos artigos do capítulo $V$ do título I do livro II do CP;

e) crimes de roubo, p. e p. pela alínea a) do.$^{\circ} 2$ e no $n .^{\circ} 3$ do artigo $210 .^{\circ}$ do $\mathrm{CP}$ - do qual resultou ofensa à integridade física ou a morte da vítima, ou o valor subtraído seja elevado ou consideravelmente elevado ou tenha ocorrido em circunstâncias qualificantes tipificadas nos n. ${ }^{\circ} 1$ e 2 do artigo $204 .^{\circ}$ do $\mathrm{CP}-$, assim como em conjugação com o artigo $211 .^{\circ}$ do $\mathrm{CP}$;

f) contra a identidade cultural e integridade pessoal, p. e p. pelos artigos do título III do livro II do CP;

g) perigo comum - incêndio, explosões, energia nuclear, incêndioflorestal - p. e p. pelos artigos 272. $.^{\circ}, 273 .^{\circ}$ e $274 .^{\circ}$ do $\mathrm{CP}$, desde que cometidos com dolo;

h) associação criminosa, p. e p. pelo artigo $299 .^{\circ}$ do CP;

i) branqueamento, p. e p. pelo artigo $368 .^{\circ}-\mathrm{Ado} \mathrm{CP}$;

j) recebimento indevido de vantagem, corrupção passiva e corrupção ativa, p. e p. pelos artigos $372 .^{\circ}, 373 . .^{\circ}$ e $374 .^{\circ}$ do $\mathrm{CP}$;

k) tráfico de droga, p. e p. pelos artigos $21^{\circ}, 22 .^{\circ}$ e $28 .^{\circ}$ do DL 15/93, de 22 de janeiro;

l) praticados enquanto membro das forças policiais e de segurança, das forças armadas ou funcionários e guardas dos serviços prisionais, no exercício das suas funções, envolvendo violação de direitos, liberdades e garantias pessoais dos cidadãos, independentemente da pena;

m) praticados enquanto titular de cargo político ou de alto cargo público, magistrado judicial ou do Ministério Público, no exercício de funções ou por causa delas;

n) ofensa à integridade física grave, qualificada e agravada pelo resultado, p. e p. pelos artigos $144 .^{\circ}, 145 .^{\circ},{ }^{\circ} 1$, alínea c), e $147 .^{\circ}$ do CP.

Da leitura do diploma legal, não se vislumbra a tipificação de crimes que integram a tipologia do terrorismo - organização terrorista, terrorismo, terrorismo internacional, recrutamento e financiamento do terrorismo (etc.) - p. e p. pela Lei n. ${ }^{\circ}$ 52/2003, de 22 de agosto.

Consideramos que, sem prejuízo de outra interpretação política e jurídica, ou o legislador entende que os crimes cometidos por os integrantes da tipologia terrorismo já se encontram identificados no catálogo do . $^{\circ} 6$ do artigo $2 .^{\circ}$ da Lei n. ${ }^{\circ}$ 9/2020, de 10 de abril [v. g., homicídios, ofensas à integridade física grave] ou entende ser desnecessário referenciar os crimes dessa 
tipologia por não existirem, em Portugal, presos condenados pelos crimes de terrorismo. Não obstante não ser esta a sede própria para debater a desorientação esquizofrénica legislativa dos últimos anos, para não dizer décadas, defendemos que quer uma opção quer outra não se nos afigura coerente com o princípio da segurança jurídica e com a função de garantia e de segurança do Direito penal ${ }^{10}$, desde logo por existir um regime especial penal para a prática de crime de uma tipologia específica e hodierna nas legislações penais dos Estados de direito matéria social democrático.

\subsection{Do perdão da pena: total ou parcial}

O sujeito beneficiário deste regime de graça perdão é o preso - recluso - por se encontrar num espaço de elevada potencialidade de propagação da dbença, o que, desde logo e não obstante a benevolência do regime e compreensão da sua aplicação concreta, poder-se-á, sob o prisma do princípio da igualdade, interrogar sobre a (in)constitucionalidade deste regime, em especial aos que foram condenados a penas de duração igual ou inferior a 2 anos de prisão face aos demais que foram condenados a penas superiores de prisão a 2 anos e do remanescente for superior a esses 2 anos, mesmo que já tenha cumprido metade da pena . Se o problema fundamento é a saúde pública e evitar quaisquer possibilidades de contágios em massa no sistema prisional, não se entende esta opção legislativa.

Compreendendo-se o escopo e benevolência da opção legislativa, conceder-se-á sempre espaço a críticas por violação dos mesmos princípios por o legislador ter, ab initio, e tendo em conta o contexto de estado de emergência e a face visível do Estado, bloqueado a aplicação destas medidas às pessoas que tenham sido condenadas e que estejam a cumprir pena de prisão por crimes cometidos contra: membro das forças policiais e de segurança, membro das forças armadas e funcionários e guardas dos serviços prisionais, no exercício das respetivas funções .

Há um oximoro face à essência básica do estado de emergência: evitar que o poder políłicoexecutivo e o poder judicial, legitimados dentro da ordem constitucional, reforce o seu espectro de ação com ampliação desmesurada da restrição ilimitada de direitos, liberdades e garantias fundamentais constitucionalizadas. Parece-nos que a Assembleia da República abriu, neste ponto, a porta ao reforço da securitização e justicialismo do Estado, olvidando a necessidade de não

\footnotetext{
${ }^{10} \sim$ Para uma leitura mais aprofundada das funções do Direito penal Valente (2020, pp. 131-138) e Faria Costa (2017, pp. 21-25)

${ }^{11} \mathrm{O}$ perdão ou o direito de graça perdão promove a abolição dos efeitos jurídicos do crime - da pena - mas não aboliu o crime, a ação delituosa, ou o processo criminal (von Liszt, 2003, p. 426), ou seja, o efeito do exercício do direito de graça não se prende com ofactum criminis, mas a efetividade da sanção (Figueiredo Dias 1993, p. 691).

${ }^{12} \mathrm{Cfr}$. n. ${ }^{\circ} \mathrm{s} 1,2 \mathrm{e} 3$ do artigo $2 .^{\circ}$ da Lei n. ${ }^{\circ}$ 9/2020 com o artigo $13 .{ }^{\circ}$ conjugado com o.$^{\circ} 2$ do artigo $18 .{ }^{\circ}$, ambos da CRP.

${ }^{13} \mathrm{Cf}$. artigo $1 .^{\circ}$, n. $^{\circ} 2$ da Lei n. ${ }^{\circ}$ 9/2020, de 10 de abril.
} 
abdicar de limites de intervenção que o princípio da igualdade exige amalgamar a cada instante e, muito em especial, em instantes e espaços de elevada restritividade da vida em sociedade.

O perdão da pena é parcial e não genérico. Não estamos perante uma amnistia ${ }^{14}$, mas um perdão concreto e parcial da pena, a mais que é individualizado e não generalizado. Só se aplica a determinados tipos legais de crime e a determinada medida concreta da pena. Poder-se-á dizer que estamos perante uma amnistia imprópria $-v$. g., perdão da pena e não perdão do tipo legal de crime fundamento da condenação [amnistia própria] (Figueiredo Dias, 1993, p. 690). Este regime pressupunha que o seu beneficiário estivesse a cumprir pena em reclusão prisional, mesmo que a pena fosse de duração igual ou inferior a 2 anos de prisão.

Aos condenados a pena de prisão igual ou inferior a 2 anos, as penas são perdoadas no seu todo, e colocados em liberdade do sistema prisional, mas em confinamento domiciliário como se encontrava toda a população portuguesa. Estes não regressarão ao sistema prisional pelo crime de cuja pena beneficiaram do perdão.

Beneficiaram deste regime todos os que foram condenados:

- a penas superiores a 2 anos de prisão que, a esta data, falte cumprir tempo igual o inferior a 2 anos de prisão, ou seja, remanescente igual ou inferior a 2 anos de prisão;

- a penas de prisão subsidiária igual ou inferior a 2 anos, por incumprimento da pena de multa;

- a pena única de prisão resultante do cúmulo jurídico, cujo remanescente seja igual ou inferior a 2 anos de prisão.

A instrução e decisão dos processos referentes a este regime de perdão couberam ao Tribunal de Execução de Penas territorialmente competente.

Do que se apurou, cerca de 2000 reclusos beneficiaram deste regime de perdão parcial de pena, o que fez diminuir a taxa de ocupação prisional, que devia ser, nesse momento, entre 75\% a $78 \%$, uma vez que não temos números concretos. Os riscos de contágio e de propagação em massa foram reduzidos com esta opção político-criminal que tem por base o princípio humanista da política criminal do ser humano (Valente 2013,pp. 174-182 e 216-223).

\subsection{Do indulto excecional}

O indulto é, nos termos da alínea f) do artigo $134 .{ }^{\circ}$ da CRP, uma competência do Presidente da República e tem como escopo extinguir, diminuir, alterar ou suspender a execução da pena aplicada transitada em julgado contra uma determinada pessoa (Figueiredo Dias, 1993, p. 688;

\footnotetext{
${ }^{14}$ Com exceção dos que haviam sido condenados a penas de prisão de duração igual ou inferior a dois anos. Considera-se que neste ponto, previsto no.$^{\circ} 1$ do artigo $2 .^{\circ}$ da Lei n. ${ }^{\circ}$ 9/2020, pode configurar uma amnistia, só não o sendo na plenitude por a amnistia extinguir, abolir ou anular o próprio crime (Cavaleiro Ferreira, 2010, II, p. 207). Guiseppe Bettiol também defende a aceção de que o perdão da pena (total ou parcial), assim como o indulto, integrantes da indulgentia principis, têm como efeito a extinção da pena, no todo ou em parte, ou a sua comutação em outra pena, e não o crime (2000,pp. 733-734).
} 
Maurach, Gössel e Zipf, 2, 1995, p. 964; Jeschek e Weigend, 2002, p. 994).

$\mathrm{O}$ indulto tem um carácter pessoalizado, individual e não geral ${ }^{15}$, a mais que tem de ser proposto pelo membro do Governo responsável pela área da justiça. Não existem indultos genéricos. O indulto extingue a responsabilidade criminal por extinção da total da pena. Mas o indulto pode extinguir no todo a pena ou em parte ou pode ainda substituí-la por outra pena mais favorável que esteja prevista em $1 \mathrm{ei}^{16}$.

O indulto, total ou parcial da pena de prisão, previsto na Lei n. ${ }^{\circ}$ 9/2020, foi excecional e prendeu-se com o fenómeno da COVID-19, devendo, nos termos do artigo 3. ${ }^{\circ}$, o requerimento preencher os seguintes pressupostos:

a) o recluso que devia ter 65 ou mais anos de idade à data da entrada em vigor da presente lei; e

b) o recluso que devia ser portador de doença, física ou psíquica, ou

c) devia ter um grau de autonomia incompativel com a normal permanência em meio prisional;

d) devia obter-se o consentimento do recluso;

e) sujeito a uma proposta - e não requerimento - de indulto elaborada pelo diretor da prisão onde se encontra o suposto beneficiário ao DGRSP, com os seguintes dados:

i. informação médica sobre o estado de saúde, física ou psíquica, do recluso e o seu grau de autonomia e a sua incompatibilidade com a normal manutenção em meio prisional;

ii. informações do recluso [processo individual];

iii. registo criminal atualizado do condenado;

iv. cômputo da pena, homologado pela autoridade judiciária competente.

f) e prévio parecer favorável do diretor-geral de Reinserção e Serviços Prisionais.

O pressuposto material exposto na supra alínea $a$ ) - 65 anos de idade - é imperativo e obrigatório, podendo ser completado com um dos dois pressupostos materiais expostos nas supra alienas $b$ ) ou $c$ ). Estes dois pressupostos eram facultativos e cumulativos com o pressuposto da idade. O pressuposto material do consentimento do recluso é condição de legitimidade de procedimentabilidade por parte do diretor do estabelecimento prisional. Não existindo

\footnotetext{
${ }^{15}$ Já no Brasil, podemos ter o indulto coletivo, em especial para "extinguir a responsabilidade de autores de crimes cuja repercussão social" e na linha de implementação de diretrizes de política criminal, conforme se retira do artigo 84. ${ }^{\circ}$, inciso XII da CRFB (Reale Junior, 2013, pp. 510-511). Em Portugal, o indulto reveste natureza individual e pessoal e concreta, contrariamente à amnistia que detém carácter geral (Figueiredo Dias, 1993, p. 689; Maurach, Gössel e Zipf, 2, 1995, p. 965). Já Cavaleiro FERREIRA equipara a amnistia imprópria a um indulto geral que extingue a punibilidade e a apena (2010, II, p. 207), assim como não afasta a possibilidade de um indulto geral de extinção de penas aplicadas (p. 208). Em Espanha, os indultos podiam ter natureza geral ou pessoal, mas neste momento os indultos gerais e abstratos estão proibidos pela Constituição de Espanha, tendo em conta que essa natureza é intrínseca à amnistia (Mir Puig, 2016, p. 798).

${ }^{16}$ Cfr. o n. ${ }^{\circ} 1$ do artigo $127 .{ }^{\circ}$ e o n. ${ }^{\circ} 3$ do artigo $128 .{ }^{\circ}$, ambos do CP português.
} 
consentimento por parte do recluso, mesmo que preencha os pressupostos materiais de $a$ ) e $b$ ) ou c), estar-se-ia sempre perante uma ilegitimidade de ação que só podia ser superada por questões de estado de necessidade justificante.

Todo este processo assente no princípio da celeridade, devia ser desencadeado e efetuado, após a entrada em vigor desta lei, em 48 horas após o consentimento do recluso, por parte do diretor do estabelecimento prisional. Após esta diligências iniciais e a receção da proposta do diretor do estabelecimento prisional, o diretor-geral de Reinserção e Serviços Prisionais remetia-a em 48 horas para o Ministério da Justiça. Os próprios reclusos, cuja situação integrasse as circunstâncias de admissibilidade legal, podiam requerer por sua iniciativa o indulto no prazo de três dias úteis após a entrada em vigor da Lei n. ${ }^{\circ}$ 9/2020, cabendo aos serviços instruir o processo no prazo de cinco dias e remeter ao Ministério da Justiça, nos termos do $n .{ }^{\circ} 6$ do artigo $3 .{ }^{\circ}$.

Os tempos estipulados são/foram de impossível cumprimento, tendo em conta que há várias diligências e diligências processuais a cumprir. Veja-se que, no dia 28 de abril de 2020, apenas tinham dado entrada no Palácio de Belém 14 propostas de indulto excecional de 492 pedidos. Não basta legislar, impõe-se a criação de condições mínimas de exequibilidade das leis de emergência como foi a Lei n. ${ }^{\circ}$ 9/2020 sob pena de descrédito e de balcanização da força imperativa e coercitiva da lei, i. e., sob pena de inutilidade normativa.

\subsection{Das licenças de saída administrativa extraordinária}

As licenças de saída administrativa extraordinária - as designadas licenças de precárias (que são limitadas no tempo) - foram pelo período máximo de 45 dias, devendo os reclusos permanecerem na habitação e ficarem sujeitos a vigilância dos serviços de reinserção social e da polícia criminal.

Esta licença podia ser renovada mais do que uma vez, por iguais períodos, desde que a conduta do recluso fosse consentânea com a medida e no contexto da pandemia. Acabando esta situação pandémica, o regime excecional extingue-se e entra em vigor o regime da execução de penas e medidas privativas da liberdade, previsto no Código de Execução Penas e Medidas Privativas da Liberdade (CEPMPL).

A licença, na linha do espírito das licenças expressas no CEPMPL podia ser revogada se o recluso deixasse de cumprir injustificadamente as condições impostas para a concessão da mesma. Esta medida é aplicada pelo diretor-geral de Reinserção e Serviços Prisionais ou, por delegação deste, os subdiretores-gerais de Reinserção e Serviços Prisionais da DGRSP.

Esta medida, do que apuramos, foi muito aplicada em alguns estabelecimentos prisionais por forma a garantir espaços que dessem resposta a uma possível contaminação e propagação da doença, garantindo isolamento interno e sob controlo e fiscalização dos serviços prisionais. 


\subsection{Da adaptação à liberdade condicional}

A Lei n. ${ }^{\circ}$ 9/2020, de 10 de abril, estabeleceu um regime especial de adaptação à liberdade condicional, sendo que que este regime conflitua com o regime previsto no artigo $62 .^{\circ}$ do $\mathrm{CP}$ português, que estipula a antecipação da liberdade condicional ao tempo máximo de 1 ano antes do início, ou seja, 1 ano antes a perfazer metade da pena.

Se $\boldsymbol{A}$ foi condenado a uma pena de prisão de 6 anos, a metade da pena ocorre perfeitos os 3 anos; o recluso, de acordo com o artigo $62 .^{\circ}$ do CP português, pode requerer/pedir a adaptação à liberdade condicional quando perfizer 2 anos de reclusão: um ano antes de perfazer metade da medida da pena.

Se aplicarmos o regime excecional desta lei, o recluso só pode requerer/pedir a adaptação à liberdade condicional quando perfizer 2 anos e 6 meses de reclusão. Ou seja, um retrocesso e não um avanço como o legislador por certo pretendeu.

Só será mais benéfico se a interpretação for a de acrescentar 6 meses ao 1 ano previsto no artigo $62 .^{\circ}$ do CP, e, assim, o recluso poderia requerer/pedir a adaptação à liberdade condicional se já tivesse perfazido 1 anos e 6 meses de reclusão. Só esta interpretação se configura com um regime mais favorável e um sistema que tem no seu espírito a proteção de vidas e da saúde da população do sistema penitenciário.

Caso assim não se entenda, este regime excecional, que se pretendia claro e mais favorável, está, na nossa opinião, em conflito com o regime previsto no Código Penal a par de ser muito mais desfavorável.

\section{Do patamar judicial de intervenção do Estado}

O patamar judicial verifica-se, a par no'quadro da intervenção do Tribunal de Execução de Penas, no essencial, em dois pontos concretos e de grande relevância face à população prisional:

- aplicação da medida de coação (medida cautelar) prisão preventiva; $\mathrm{e}$

- reexame dos pressupostos fundamento da medida - ou seja, na prossecução de um reexame extraordinário -, não havendo qualquer necessidade de se respeitar o prazo de 3 meses, previsto no artigo $213 .^{\circ}$ do CPP português.

Estas duas dimensões devem ser tidas em conta muito em especial para as pessoas com 65 ou mais anos de idade à data da entrada em vigor da presente lei, que fossem portadoras de doença, física ou psíquica, ou detivessem um grau de autonomia incompatível com a normal permanência em meio prisional.

Mas consideramos que, não obstante os vocábulos «sobretudo» ${ }^{18}$, a aplicação do artigo $7 .{ }^{\circ}$

\footnotetext{
${ }^{17}$ Cf. artigo $7 .{ }^{\circ}$ da Lei $.{ }^{\circ} 9 / 2020$.

${ }^{18}$ Para uma leitura crítica, sem entrar em grandes questões de constitucionalidade, mas de uma igualdade ao tratamento diferenciado aos mais vulneráveis face à pandemia se pode ler o artigo do juiz Pedro Soares de
} 
em conformidade com a Constituição portuguesa exige que estes critérios se apliquem a todos os presos preventivamente independentemente dos tipos legais de crime fundamento da aplicação da medida de prisão preventiva, cuja análise e reexame deve ter sempre presente os artigos 191. ${ }^{\circ}$, $193 .^{\circ}, 202 .^{\circ} \mathrm{e} 204 .^{\circ}$ do CPP português em conformidade ou de acordo com o artigo $18 .^{\circ}, \mathrm{n} .{ }^{\circ} \mathrm{s} 2 \mathrm{e} 3 \mathrm{e}$ $28 .^{\circ}$ conjugados com o artigo $13 .^{\circ}$, todos da CRP.

Os tribunais tiveram especial cuidado quanto a esta dimensão interventiva do Estado, diminuindo a aplicação da prisão preventiva em prol de obrigações de permanência em habitação com e sem vigilância eletrónica, e procederam a reexame extraordinário, notificando os advogados de presos preventivos para informarem se os seus constituintes se enquadravam nos pressupostos pessoais: 65 ou mais anos, portador de doença ou portador de uma autonomia incompatível com o meio prisional. Poder-se-á dizer que são inúmeros as decisões e acórdãos que materializaram o espírito destas normas.

\section{Conclusões breves}

Houve, nesse tempo, uma tentativa de materializar o princípio da humanidade enquanto princípio da política criminal que deve integrar em si mesma uma política pública de saúde holística, em que ninguém deve ficar para trás. Poder-se-á afirmar que RADBRUCH tem razão quando afirmou que a verdadeira reformar ou alteração legislativa penal deve preocupar-se "não tanto na criação de um direito penal melhor" do que o vigente, mas com "um direito de melhoria e de conservação da sociedade: alguma coisa de melhor que o direito penal e, simultaneamente, de mais inteligente e mais humano do que ele" (1997, p. 324).

O legislador em tempos de pandemia considerou que havia outras opções melhores que a manutenção estrita e implacável do direito penal na dimensão da execução da pena de prisão, cuja necessidade de privação de liberdade, associada a um sentido de humanidade e de necessidade, impuseram uma opção de primazia da liberdade subsumida a uma autorresponsabilidade no cumprimento das medidas judicialmente impostas.

\section{Referências}

ALBERGARIA, PEDRO SOARES DE. Nótula sobre o âmbito objectivo e subjectivo da obrigação de reexame dos pressupostos da prisão preventiva na L9/2020, de 10 de Abril. In: Julgar - Online, abril de $2020 \mid$ 1, pp. 1-6.

Beccaria, Cesare. Dos Delitos e das Penas. Tradução do italiano Dei Delitti e Delle Pene de José de Faria Costa. Lisboa: Fundação Calouste Gulbenkian, 1998.

Bettiol, Guiseppe. Direito Penal. Tradução do italiano Diritto Penale (Parte Generale) de 1962. 
Campinas: Red Livros, 2000.

COSTA, JOSÉ DE FARIA. Direito Penal. Lisboa: INCM, 2017.

DELMAS-MARTY, MIREILLE. Le Flou du Droit. Paris : PUF, 1986.

DiAS, JORGe De fIgUeIREDo. Direito Penal Português. As Consequências Jurídicas do Crime.

Lisboa: 1993.

FERRAJOLI, LUIGI. Derecho e Razón. Teoría del garantismo penal. Traduzido do italiano Diritto

e Ragione. Teoria del Grantismo penale de Perfecto Andrés Ibáñez et Alii. Mardid: Editorail trottal, 2005.

FERRI, ENRICO. Princípios de Direito Criminal. O Criminoso e o Crime. Tradução do italiano da edição de 1931 por Luiz de Lemos D'Oliveira. Campinas/SP: Russell, 2003.

JESCHEK, HANS-HEINRICH e WEIGEND, ThOMAS. Tratado de Derecho Penal. Parte General. 5.

Edição. Tradução do alemão Lehrbuch des Strafrechts: All. Teil de Miguel Olmedo Cardenete, 2002.

LISZT, FRANZ VON. Tratado de Direito Penal - Tomo I. Tradução do alemão Lehrbuch des

Deutschen Strafrechts de José Higino Duarte Pereira. Campinas: Russel Editores, 2003.

maurach, Reinhart, gÖssel, Karl heinz e ZiPf, heInZ. Derecho Penal. Parte General - 2. Tradução do alemão Strafrecht Allgemeiner Teil . Teilband 2 de Jorge Bofill Genzsch. Buenos Aires: Editorial Astrea, 1995.

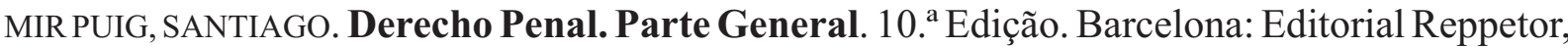
2016.

MONTE, MÁRIO FERREIRA. Da realização integral do direito penal. In: STVDIA IVRIDICA 90 AD HONOREM - 3 - ARS IVDICANDI - Estudos em Homenagem ao Prof. Doutor antónio Castanheira neves - volume III: Direito Público, Direito Penal e História do Direito. Coimbra: Coimbra Editora, 2008, pp. 737-771.

OTERO, Paulo. Direito Constitucional Português - I - Identidade Constitucional. Coimbra: Almedina, 2010.

. Instituições Políticas e Constitucionais - Volume I. Coimbra: Almedina, 2007.

PRADEL, JEAN. Traité de Droit Pénal et de Science Criminelle Comparée. 12. Édition. Paris: Éditions Cujas, 1999.

RADBRUCH, GUSTAV. Filosofia do Direito. 6. ${ }^{\text {a }}$ Edição. Trad7ução do alemão Rechtsphilosophie de

L. Cabral Moncada. Coimbra:Arménio amado, 1997.

ReAle JUnior, Miguel. Instituições do Direito Penal - Parte Geral. 4. a Edição. São Paulo: Forense, 2013.

Valente, manuel monteiro guedes. Direito Penal do Inimigo: O «Progresso ao

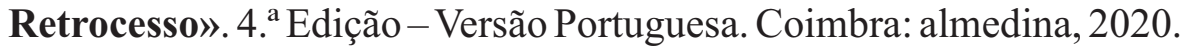

. Os direitos humanos e o direito penal: uma (re)humanização emergente. In: STVDIA 
IURIDICA 109 Ad Honorem - 8. Estudos em Homenagem ao Prof. Doutor Manuel da Costa Andrade - Volume II: Direito Penal, Direito Processual Penal. Coimbra: INSTITVTO IURIDICO, 2017, pp. 281-301.

- Do Ministério Público e da Polícia. Prevenção Criminal e Acção Penal como Execução de uma Política Criminal do Ser Humano. Lisboa: Universidade Católica Editora, 2013.

. Natureza Jurídica do Corpo da Guarda Prisional. Lisboa: EDIUAL - CIDCJ da UAL, 2008. 